\title{
ON THE PERFORMANCE OF PLAYBACK FOR DEAD MEDIA DEVICES
}

\author{
Matthew Hockenberry and Jason LaRiviere
}

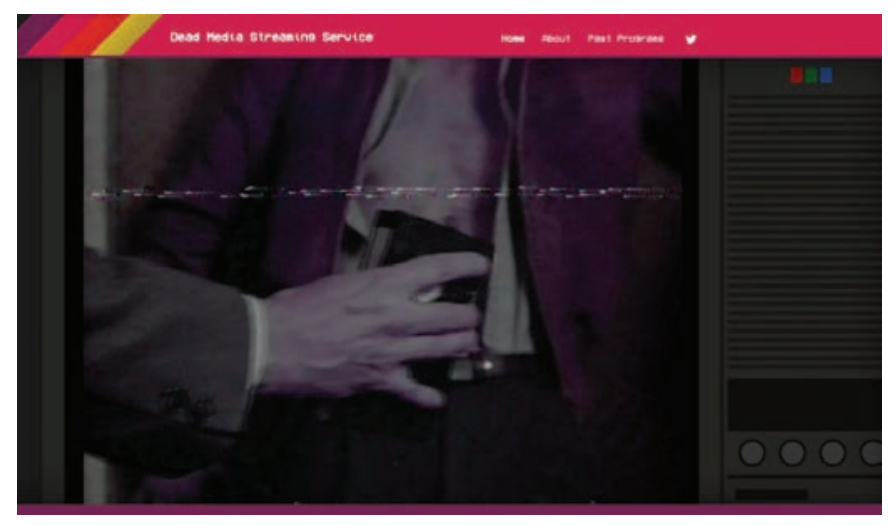

FIGURE 7.1 Performance of Videodrome (1982) on the Dead Media Streaming Service.

David Cronenberg's 1982 masterpiece Videodrome depicts a very peculiar act of media consumption. After viewing a televised sermon from Brian O'Blivion, the film's McLuhan-esque techno-profit, protagonist Max Renn (played by master of postmodern smarm, James Woods) develops a rare condition: a large slit opens in his abdomen for access to the wetware of Max's internal organs. The high concept gambit of Cronenberg's film is typically read by cinema scholars as a symptom of his overarching concern with "body horror" - an investigation into the uncanny permeability of the human body explored in films such as Scanners (1981) and The Fly (1986). But here it is media itself that has the ability to interpenetrate the body's soft exterior. As Steven Shaviro puts it, "Video technology is no longer concerned merely with disembodied images. It reaches directly into the unseen depths, stimulating the ganglia and the viscera, caressing and remoulding the interior of 
the body" (Shaviro 1993, 142). The strategy of Videodrome, he explains, is to take theorists like McLuhan and Baudrillard at their word, to "overliteralize their claims for the ubiquitous mediatization of the real" (Shaviro 1993, 138). At a crucial moment in the film's final act, Max has a videotape inserted into his body that brainwashes him into going on a killing spree, eventually resulting in his own suicide. Perhaps, the viewer is meant to assume, he is just another victim of too much media exposure.

If most critics agree about the moral of Cronenberg's ending, what is not often remarked upon is the format of the tape that brings about the bloody denouement: Betamax, Sony's entry in the home video format wars that began in the late 1970s (Benson-Allott 2013, 70-101). One might imagine that by making a Betamax cassette - the "late lamented Betamax," as Cronenberg puts it - the "preferred Videodrome format," the director was suggesting something significant. After all, Max's death prefigures the "death" of this media format at the hands of VHS only a few years later. The truth is more material. "It was smaller", Cronenberg explains, a better choice to fit into "strange places" (Cronenberg 2004). When the Dead Media Streaming Service screened a Betamax copy of Videodrome at the end of July 2017, it was again forced to fit into a "strange place". The service, which streams obsolete formats to the web from original hardware, seemed to permit a similar act of parasitic interpenetration to take place. The Betamax tape was remediated, transformed into something old and new - strange and mutated.

\section{The analogue undead}

What does it mean to press play? There was a moment before the advent of digital video where this process was the culmination of some careful preparation, and this nostalgic history of the salad days of the video store - along with its attendant cultural rituals - has become something of a scholarly genre (Herbert 2014). It begins with walking the shelves of the store. Making the selection. Popping popcorn after the long drive home. Dimming the lights. Freeing the film from its clamshell case. Finally, there is the familiar resonance of the VCR's tape head moving into place. Click. Whrr. Action. Even then, there were countless rites that consumed the night. Adjust the tracking. Fumble for the remote. Pause. Play. Rewind.

The first showing on the Dead Media Streaming Service, with no advance notice and only a little fanfare, was 1980's infamously bad rock opera, The Apple. The copy in question - the Betamax home video release from Cannon Film - was a poor recording of what is already considered an unwatchable movie. Nothing as transformative as Videodrome. Still, when the play button was pressed on the 30-year-old player an entirely obsolete format was brought back to life: its crackling audio and fuzzy images streaming out to any viewer who might have happened to follow the link. Presenting a home video in this way was intended only as a technical demonstration, a proof-of-concept for a web-based video service we had developed. We had no idea how well the tape would perform, if anyone would tune into the broadcast, or, indeed, if the system would come 
together at all. This performance, this media archaeological experiment, was not without its problems. The tape constantly fell out of sync, and the continuous tracking adjustment required proved especially tedious over the course of multiple showings. But it was not without some measure of success, an undeniable tremor of transformation. Indeed, since that impromptu opening dozens of films have been screened for the community gathered around the service, with a mandate to not only present at least two each month over the regular academic term, but to incorporate them into courses in media archaeology and media history as we develop our own sort of parasitic pedagogy out of the performance of the obsolete.

The sort of programs that are performed on the service vary. Some are meticulously planned, requiring considerable time and effort to acquire the appropriate movie on the appropriate format. It took more than a year to obtain Videodrome on Betamax, but no other copy would do. Other screenings, like our memorial presentation of Night of the Living Dead on VHS for director George Romero, Aliens on Laserdisc for Bill Paxton, or Purple Rain on Betamax for Prince, had to be assembled in response to more unexpected circumstances. Most are organized thematically, either as compilations such as our "creature feature" of the cultclassic Hardware and the campy Saturn 3, series like our "cyberpunk" summer of The Net, Strange Days, Hackers, and Blade Runner, or for specific events - Halloween on Halloween, Ladyhawke coinciding with a solar eclipse. Over the "life" of the service we've programmed everything from The Last Dragon on Betamax and The Peanut Butter Solution on VHS, to Battle Royale on VCD and Lady Snowblood on Laserdisc. The only requirement for a selection is that the format on which it will be presented is obscure, obsolete, or otherwise dead.

The question at the heart of this practice is what it once meant to press play on these obsolete objects - and, perhaps, what it could still mean. There was a moment when it seemed that cinema itself could be contained in plastic shells,

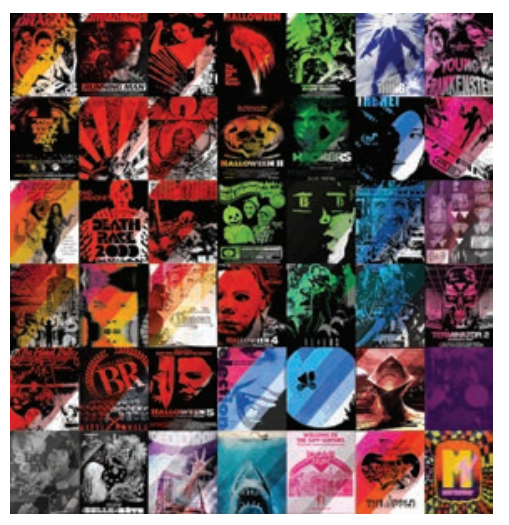

FIGURE 7.2 Custom posters for some of the home video releases screened on the service. 
made manifest on magnetic tape. But with video streams encoded for almost every device imaginable, an isolated apparatus for the reproduction of outdated electrical signals has become an unthinkably archaic appliance. Heaps of discs, tapes, cassettes, and cartridges sit idly by, mouldering in dusty attics and damp basements. As Jonathan Sterne has suggested, our expectation of technology's eventual obsoleteness brings with it a painful truth: new media always becomes old (Sterne 2007, 16-17).

Media archaeology must always begin from what Wolfgang Ernst calls the "media assemblage," a device that is technologically - and therefore historically "operational". But the effort to excavate these remains brings with it, he muses, a surprisingly "haptic taste" for the "mouldy, decaying fragments" that constitute the "mummies, parchments, [and] remnants" of media technology (Ernst 2005, 589). Perhaps as a consequence, our attempt to instil a new means of meaning has fallen victim to what Garnet Hertz and Jussi Parikka have called "zombie media." Less dead media, more "media undead". With these "living dead of media history," we are not concerned with media in use, but media "resurrected to new uses." No wonder the stream of Romero's Night of the Living Dead was one of the most successful! By "probing, exploring and manipulating" consumer technologies beyond their natural life spans, our analogue undead stagger into unexpected and entirely unfamiliar contexts (Hertz and Parikka 2012, 427-429).

\section{Programs for streaming software}

Rather than Romero's cemetery in western Pennsylvania, we turn to a website in Manhattan's Greenwich Village. Through it, we watch the reanimation of early video formats for life in the digital age. Despite the uncertainties that accompany these phenomena in the movies, the happenings here aren't quite so mysterious. Indeed, from a purely technical perspective, they require only a modest amount of hardware. Some off-the-shelf, some in the junkyard. From the latter, a media capture station to interface with otherwise derelict media players, converting their analogue audio/video formats to contemporary digital signals. From the former, a relatively standard media server managing the published stream. Through this arrangement, we are not limited to already receptive spaces like those of Max Renn's Toronto. More remote geographies with more limited infrastructural resources - the flea markets and thrift stores that will constitute the grave-sites of most media - become equally viable sources for dissemination. A veritable horde of dead media devices.

Working with these formats in the current moment, acquiring the "haptic taste" it requires, is a more difficult proposition than it might seem. Contemporary video practices revolve around software for editing high definition digital signals not magnetic tape decks and specialized effects boxes. Students rely on ports prepared for compliant HDMI and SDI interfaces, not the unmediated electrical connection of RCA-style composite video jacks, BNC connectors, or SCARTstyle plugs. The material world of analogue video has not only fallen by the wayside, 
it is rotting there. Circuits necessary to process the curiosities like composite and component video are out of production, discontinued. Ancient artefacts of an earlier era.

The transition to digital video was marked by signs of sacrifice. New forms of content control were carried along with unfamiliar connectors and cables, complete with compression artefacts, evidence of over processing, and an entirely new set of errors and irritations. "Squeezed through slow digital connections, compressed, reproduced, ripped, [and] remixed," Hito Steyerl opines, "only digital technology could produce such a dilapidated image" (Steyerl 2009). But, like most moments of transition, the past isn't easy to see from the other side. It is now the analogue image that is in disrepair, and the gap between the past and the future cannot be kept open indefinitely. Modern devices are tuned for capturing $4 \mathrm{~K}$ and VR, not comparatively primitive DV streams. The very image of current day HD televisions can seem out of focus for filmmakers who are actively appropriating a retro look and feel for their productions. Matt and Ross Duffer, creators of the Netflix series Stranger Things, have been outspoken in their criticisms of the default "motion smoothing" of most contemporary screens. When watching their show a self-conscious mélange of 1980s horror tropes attributable to icons of the genre like John Carpenter, Stephen King, and Steven Spielberg - they encourage viewers to turn off features like "TruMotion" or "smooth motion" (Sternbergh 2017). But it is a futile request. Like modern televisions, streaming services like Twitch and YouTube expect pure digital signals at the highest frame rates, pure digital production for pure digital playback - the output of digital devices intended as the inputs for yet another digital device.

The result is that it can seem like we are struggling to speak analogue in a digital world. But we should not forget its basis in that ancient dialect. Before releases were described with generic ubiquity as media (or worse, content), industry sources referred, quite simply, to "software". While this might evoke a sense of the alwaysalready digital, at the time this was just a way to suggest "something that went into a machine", marking their suitability for playback on the comparatively hardware of a turntable or tape-deck. While Joshua Greenberg suggests that distributors "were marking out a specific relationship between pre-recorded tapes and video recorders" that had the consequence of ignoring video cassette's materiality, this might be the very metaphor that allows us to recover the implications of that materiality (Greenberg 2008, 55-56). In a moment where everything already seems to be software, it may be just the right kind of language for bringing the dead back to life.

It opens avenues to some other metaphors as well. Emulators and fieldprogrammable gate arrays are only some of the means by which software's old incarnations still persist, alive and "running" on new devices. Retrocomputing enthusiasts will speak about having a "tweener" - a computer that is "in-between", as it were, the truly old and obsolete. They support prior disk formats and drives, previous card interface and ports, but they feature more accessible networking, more flexible storage solutions, and more recent operating systems (see, for example, Vintage Computer Federation 2011; Lineback 2017). The most useful are often 
the last generation of a system to support certain capabilities, and - while its Thunderbolt support positions it partially toward more recent cameras and capture devices - the most obvious benefit for obsolesce from our mid-2011 Mac Mini is found here. Firewire, the high-throughput serial interface designed to replace the aging SCSI standard, prefigured the oncoming ubiquity of digital video. "It wasn't long ago that video on the desktop was more fiction than fact," PC Magazine wrote in 1997. It was only through technologies like Firewire that it had finally become "reality" (Ozer 1997, 159). As the first widely implemented standard for working with digital video, Firewire became a fixture on the final generations of tape-based digital camcorders that had begun to store digital, rather than analogue, video. As a consequence, a wide range of consumer devices were produced with analogue inputs and digital outputs capable of reliably converting the formats used by tapes, cartridges, and discs to the early digital video (DV) codec. Indeed, we make use of Canopus AVDC converters precisely because of their support for DV over Firewire. But it is a temporary solution. Most computers that support this workflow have, themselves, become period pieces - back from fact, to fiction.

While the conversion to digital video is a complex requirement for any nonanalogue transmission of dead media, the requirements for constructing a streaming server capable of delivering the results remain relatively modest. While there is some irony in the fact that our only hardware failure has been with the new, rather than the old, in practice nearly any computer will suffice. For our service, we have symbolically set a RaspberryPi into an otherwise ordinary Betamax cassette case. The Nginx server running on this box allows the contents of this cassette to be "played" over an RTMP stream or through the HTML5 video player loaded into the site. It also provides the basic software structures required for operating the community around the service - both its web presence and the storage necessary to collate archived video files from prior performances.

Our Betamax box is a rogue media server. Though consumer-facing streaming services have become increasingly commoditized for players of video games,

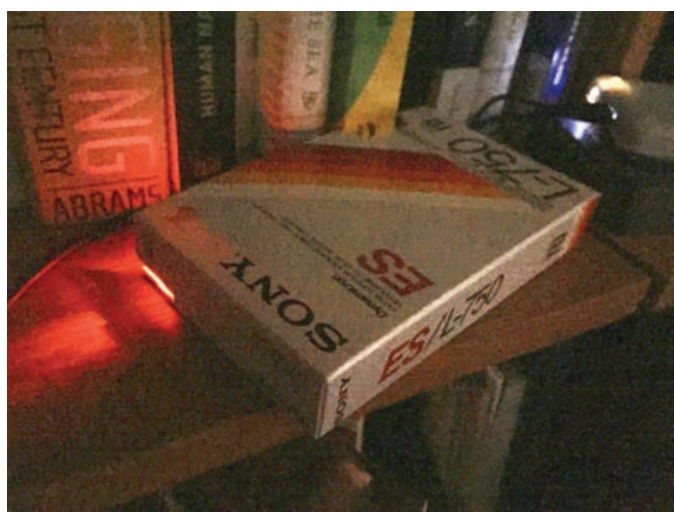

FIGURE 7.3 Betamax streaming server. 
both retro and recent, they have proved problematic when applied to other media objects, with the terms of the largest services, Twitch, YouTube, and Facebook, prohibiting these broadcasts in compliance with the legal requirements of the DMCA (see Jenkins, Ford, and Green 2013, 49). Policies remain highly contingent, with much of the vernacular traffic in dead media archives falling victim to digital fingerprinting and copyright protection technologies (with YouTube channels like Techmoan and Oddity Archive, both of which regularly demonstrate obsolete media formats and technologies, offering valuable insights on the amount of content one can safely show and what countermeasures are necessary to avoid triggering these automated responses). While we have no illusions about the legal status of the works we broadcast, it seems reasonable to differentiate when they are no longer, for most definitions of the term, playable. If this was more conventionally credited software, we might describe them as "abandonware". The fact that we can't stems largely from the extensive back catalogues of modern media companies. Almost everything will be re-released. That they come to us as digital remasters, special editions, and deluxe features suggests that the objects we are interested in reanimating have not always been left behind. They've been replaced.

\section{Forms and formats}

Every screening on the service begins the same way. A particular title is selected and the format is found. The object - tape, disk, cassette, or cartridge - is tested and tuned. Any details necessary for playback are noted. At the scheduled time, the appropriate equipment is prepared. Hitting play on the deck begins the broadcast, converting the original object to a digital signal streamed out on the service. Adjustments to tracking, the switching of tapes or discs, and any other operations necessary for viewing must be performed, live, over this initial broadcast. As a result of this process, a recording - for our purposes, an "archival" representation of the event - is created by the streaming software. Despite the reproductive promise of the recording, each event is an individual performance, with a unique set of constraints and demands. While entire boxes of VHS tapes may require only a few adjustments over the course of playback, the more venerable Betamax can require multiple machines, with multiple, misaligned, tape-heads, to produce any image at all. Laserdiscs, with their manual movement between the sides of a disc and awkward assembly of special features, exact their own concessions in the sorting of sleeves. For our students, this software "programming" reinforces the particular temporality and materiality of these objects. Magnetic tapes are formed and formatted by the players they get played on. The split sides of laserdiscs are gaps in the continuity of presentation, just as they are openings to unexpected places. Just as long-lost images have been recovered in the margins of film leaders, Tromo collaborator Richard W. Haines recalled that the technical constraints of laserdisc manufacture required signal on the side not intended for playback, with this "dead side data" accessible to those pioneering media archaeologists willing take a chemical solvent to their discs (Haines 2003, 135). 
Relatively early in our process we made the decision to limit the more mechanical aspects to the initial screening, to allow "reruns," so to speak, from the video file produced by digitization. While one consequence was that we were able to make screenings available in a rotating "video on demand" feature, the primary motivation was that for most movies it was overly tedious to manage the particulars of a "live" performance for an extended period of time. For some it was almost impossible. The ideal circumstance for streaming a laserdisc, for example, requires only that one is fully committed to the presentation - watching the program carefully to respond to the request to flip discs and restart playback, noting the timing of each transition for when a manual procedure will be required. But a poorly preserved Betamax tape requires almost continuous active adjustment. While this might be a reasonable hazing activity for a new programmer, it is unreliable as part of a regular practice. Automation is possible, of course. Algorithms can be written, mechanical intermediaries constructed. Playback can be triggered by networked infrared emitters (for devices equipped with remote controls), but even this requires the media be physically present (though more popular formats might offer multiple-device systems - multi-disc CD players or dual-tape VHS decks, for example). It seems that these media always require a little bit of fiddling alongside their particular presence in space and time. Always messier and more material than we might imagine.

This materiality is something that becomes almost immediately clear to any viewer of the stream. Or rather, it doesn't. For those used to the high-resolution imagery, crisp and complex audio encodings, or smooth movement and perfect frame rates on Blu-rays and digital download services, the differences of older formats can come across as deficiencies. They are copies, imitations, and poor ones at that. But this comes from a very particular way of looking, one premised on the idea that there is some original that this copy stands against. Before the days of digital cameras, films were shot on film, and so it is certainly true that there did exist a single material object that was, for all meaningful purposes, the film. The existence of a "master" carries with it the understanding that there was some ideal to which all iterations must be compared. But despite the perfection of its appearance, a digitally "remastered" release of an analogue artefact is no more materially like the original than any other. It has been re-encoded, re-presented, and re-animated for an entirely different format - one with entirely different capabilities and curiosities. The transition to the digital brings with it an embrace of a digital aesthetic, with pixels, rather than lines, of resolutions; with frame rates intended for LCDs and OLEDs, not projectors and cathode rays. While this new regime of visual fidelity is taken to present a superior picture from the media of analogue mediums, this sort of fidelity is no more faithful than any other. Nor does digital production imply an exact duplicate. Encodings and compression ensure that few will see the same sequence of ones and zeros that defined the original. They all just pieces of software, each just another format. To embrace the "economy of the multiple," Erika Balsom writes, is to recognize how meaning shifts to the channels through which these copies will flow (Balsom 2017). In the history of home viewing, most 
consumers before the 1980s settled for Super 8 reproductions, "highlight reels" that were compressed down to a few scenes and which ran at less than ten or twenty minutes. When the end of the 1970s brought the opportunity to see a film in full, it did so with the seemingly obvious and inconsequential caveat that they were, indeed, no longer films.

As Jonathan Sterne has put it, the dominant mode of media history depends on the imagination of a particular sort of verisimilitude, where progress can only be imagined as "progress in terms of greater and greater definition" (Sterne 2015, 35). Certainly the logic of this paradigm was familiar to manufacturers in the home media industry, and companies like Sony and JVC readily declared the heightened fidelity of many of the components they released. But they rarely applied this language to home video, where the emphasis was largely on the capability to move media from one place and time to another. The only claim to quality was to the length of the feature - an entire film rather than the edited selections that had been available on formats like Super 8. "Watch whatever, whenever", as Sony suggested in 1978.

But media forms, Sterne counters, "are not like suitcases; and images, sounds, and moving pictures are not like clothes". There is no definitive edition to be found. There are only different definitions, and despite the claims of early video sales that cassettes could put "Hollywood in a box", Sterne reinforces that media objects have "no existence apart from their containers and from their movements or the possibility thereof' (Greenberg 2008, 55-56; Sterne 2015, 35-36). Different formats are not interchangeable; they cannot be played just anywhere. At best, they are "ports", alternative instantiations for the subtleties of the systems on which they are released. Anyone who has listened to Sgt Pepper's Lonely Hearts Club Band on 8-Track or played Assassin's Creed on their mobile phone can attest to the fact that the limitations of these platforms impose demands on their porting practice.

These new demands call for new ways to conceptualize them. The turn to a focus on formats, in other words, ought to give rise to format theory. "If there is such a thing as media theory, there should also be format theory", entreats Sterne $(2012,7)$. Figured in this way, the Dead Media Streaming Service can be taken as an attempt to put something of this into practice. By foregrounding the format specificity of each individual stream, by emphasizing the historical and material contingency of a particular remediated experience of an obsolete format, the service's programs resist the teleology of verisimilitude that Sterne locates in a traditional account of communication history that "outlines a quest for definition, immersion, and richness of experience" (Sterne 2012, 4). By refusing the "a priori hierarchy of formations of any given medium", and recognizing that communication has a "network reality" - not a binary relationship of mediated transmission, but rather "an ensemble of relations that only produce the moments of transmission and reception after the fact" - format theory invites us "to ask after the changing formations of media". We begin to consider not only the "contexts of their receptions", but "the conjunctures that shaped their sensual characteristics", and even "the institutional politics in which they were enmeshed" (Sterne 2015, 35-35; 
2012 , 11). To pursue this alternate path, as we wish to do, is to explore the intriguing swerves, the missed opportunities, and the outright failures that have piled up as the angel of media history backs itself into the increasing ubiquity of digitalization.

\section{Optical media}

Laserdisc is only one example of the persistence of the service in following this path. Students struggle to make sense of these strange and mysterious "oversized CDs". Indeed, quite unlike CDs, DVDs, and most other formats that are read optically, laserdiscs are largely analogue objects. Though they seem to share some perceptual connection to DVDs, they have no native capability for "menus", for "soft" removable subtitles, or the other programmable video features that debuted with that format. They aren't defined by the sampled sources of the DVD codec, but by a composite video stream inscribed on plastic pressed 12" aluminium platters. At its release, laserdisc held a justifiable claim to a superior video format, with a staggering 425 lines of horizontal resolution compared to VHS's 240. But while it began with an advantage over the mechanical complexity of video cassettes, a combination of economic and technical limitations (it was a read-only format), relegated it to the margins of mediation. Marketed to cinephiles, it struggled to compete even with expensive - but more reliable - film prints.

The format not only persisted, it pioneered features that became permanent fixtures for the future. The capability for multiple audio tracks (both analogue and digital) not only permitted multiple language imports, it allowed distributors like Criterion to experiment with commentary tracks. Its position outside the mainstream allowed it to stretch the limits of analogue television's 4:3 aspect ratio, with countless widescreen releases over the format's life. While the format held no more than 60 minutes of video per side, many included a frame-perfect, 30-minute, constant angular velocity (CAV) encoding on the second disc - presenting the dramatic climaxes common to blockbuster action films with the potential for frame-by-frame follow through, slow-motion, or reverse tracking trick-plays. The availability of a "fourth side" on these releases led to the inclusion of special features like trailers, production art, and making-of documentaries, while clever uses of chapter markers and automatic pausing prefigured the more sophisticated menuing of later optical formats. The result was that laserdisc became a connoisseur format (Klinger 2006, 54-90). At the height of this phenomenon acrylic platters proliferated. Special editions could include as many as six discs, and multiple versions of a particular film, with alternative editors and director's "cuts". Copies of copies for a cinephile's delight.

It is remarkable how many of the unique features of laserdisc emerged because of the peculiar properties of the format. Late in its life, VHS began to mimic traits that had become common to laserdisc and DVD, including widescreen editions and special features. But even though these formats came to copy the conventions, they'd never had the same technical constraints - the extra sides to fill - that laserdisc had. While Betamax cassettes were more constrained, VHS distributors 
had rarely been limited by the amount of tape they could spool inside their shells. For the few features that did come on two (or more) tapes, divisions were set at entirely arbitrary points. But there were exceptions. When Gone With The Wind was designed to break at the same point that the theatrical release had its intermission, the recording media seemed to have captured a material reminder of the previous format. As Wolfgang Ernst notes, media archaeology, "is both a self-reflexive method and an archival object of research". For a digital culture of "apparent, virtual, immaterial realities" this sort of reminder - of the "insistence and resistance of material worlds" - is, he writes, "indispensable" (Ernst 2005, 589).

Our media formats will always come burdened with their own limitations. But even overcome by technological development, they give rise to entirely new ones. In cinema, directors were originally constrained by the physical size of the film reel that could fit on the camera. When Alfred Hitchcock, to offer one prominent example, wanted to make his Rope a one-take, uninterrupted, single shot, the tenminute maximum provided by a standard reel of $35 \mathrm{~mm}$ forced the director to find creative ways to "hide" his cuts - moving the camera behind a character's back, lingering on a dark prop, and so on (see Bordwell 2008). At the exhibition stage, this constraint was marked, quite literally, by the "cigarette burn" in the corner of the frame that signalled a reels' end (a feature immortalized by Brad Pitt's anarchistic projectionist in Fight Club). When the dream of the single-take feature finally became a reality through the storage capacity of digital cameras, in "films" like Alexander Sukorov's Russian Ark, it was accompanied by the oncoming ubiquity of digital projection. Seeing celluloid became a boutique cinephile practice. The need for a break between reels all but disappeared.

But not all interruptions were the result of technical limitations. The intermission is a break, a stoppage in a performance. For a time in the twentieth century, the roadshow theatrical presentation was the ultimate mark of a "prestige" production. Epics like Gone with the Wind or David Lean's Lawrence of Arabia included intermissions, along with overtures, exit music, elaborate lobby ephemera, and souvenir programs - all of which contributed to the special sense of the experience. These films were typically longer than the average feature, upwards of four hours, and these breaks were no doubt welcomed. Be it for dramatic effect or for comfort, the entr'acte is a cultural technique that can be traced across a number of historical contexts and performance practices - from the act breaks of eighteenth century opera to flipping a laserdisc to play the other side. By "cultural technique" we have in mind the German concept of Kulturtechniken that has emerged as a key approach in continental media studies. As Bernhard Siegert explains, "The concept of cultural techniques highlights the operations or sequences of operations that historically and logically precede the media concepts generated by them" (Siegert 2011, 15). Figured in this way, the interruption of performance becomes a recursive historical operation that has always already preceded our current media theoretical conception of it. And some, at least, might be creatively remediated, from the public time of the roadshow intermission to the private time of the disc flip and the pause button. 
This sort of remediation is all the more necessary in a media landscape where the proliferation of digital files has served to mask the differences between formats. Not that digital distinctions are any less significant. After all, two digital music files, alike in representation save for the .MP3 or.WAV appended to their names, nevertheless stand at the end of processes of production with little else in common. The former is a lossy data compression format founded on psychoacoustically modelled samples; the latter is a "raw", uncompressed, bitstream. Even this description neglects the multitude of differences that lurk within files of the same supposed type. Break them open and a whole host of encodings and corresponding codecs start to spill out. These are distinctions that have become remarkably less distinct. While there was a point in the heyday of the MP3 where at least one feature - filesize - was readily apparent to any bandwidthbound user, that day is long past. Even the idea of the file, itself, is fading. Nearly everything seems to play inside the same sorts of apps, lost somewhere out in the stream.

Through our return to the more obvious artifactuality of analogue media forms, we hope to find ourselves better able to see the crystallizing conditions for the "social and material relations" that give form to all of our formats (Sterne 2006, 826). As we do, we come to all sorts of remarkable realizations about the logics that structured them. We see, for example, that despite the perception of physical incompatibility, analogue formats were sometimes more forgiving than their digital counterparts. Digital files cannot open outside their expected applications, but Betamax tapes will "play" a haunting magnetic motion inside a VHS shell. PAL formatted video will display strange signals when NTSC devices work to process them. The flexibility of these formats, the shock of our students reminds us, has been lost somewhere along the way. Our media objects, it seems, can no longer fit into quite as many strange places as they could before.

\section{Pedagogy of performance}

While the service has been utilized in a number of undergraduate and graduate contexts, including in our Dead Media Research Studio and by students studying in the Technology, Culture, and Society department, we are particularly invested in its ability to provide a "hands on" experience for media studies students new to media archaeological practice. While many of those interested in media archaeology come from backgrounds with some degree of technical skill, few occupy quite the same celebrated position of Friedrich Kittler's "technological bricoleur" who writes on media theory by day and works with "soldering gun in hand and DOS screen in view" at night (Peters 2010, 7). Coupled with the demanding expertise of foundational media archaeological theorists like Kittler, Ernst, and Siegfried Zielinski, media archaeology presents a formidable front. "Programming" for the software of the service offers a practical entry point for those for whom Assembly Code and $\mathrm{C}++$ are not native languages. This sort of programming not only presents an opportunity for students to learn about dead media forms and formats, it 


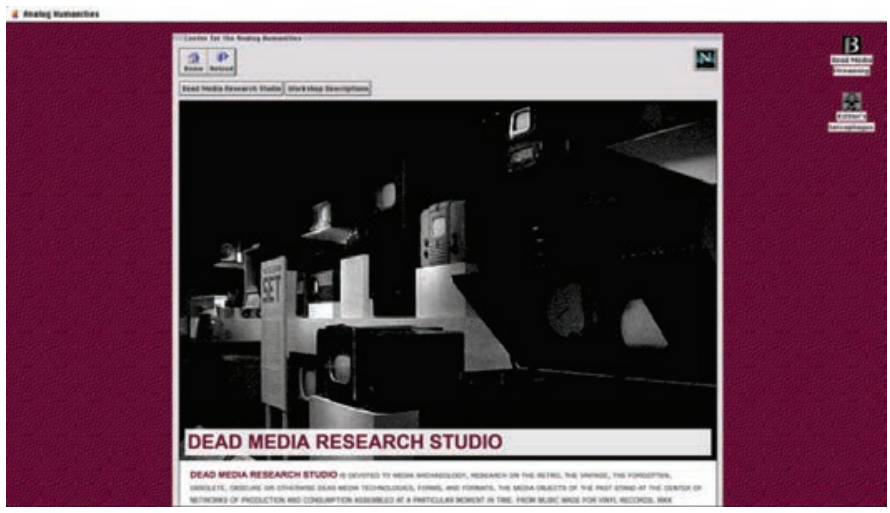

FIGURE 7.4 Curriculum for use with the Dead Media Streaming Service.

provides them with a crash course in the basic techniques necessary for their acquisition, exploration, and preservation. Students learn to recognize the unfamiliar and unexpected sites of media archaeological investigation, cataloguing an everchanging list of flea markets, vintage shops, and dumps. They become familiar with the vernacular traffic in old media formats, developing connections to communities where practitioners discuss techniques and equipment in vintage electronics forums and perform them in the course of creating retro-nostalgia video series. Students have the opportunity, in other words, to get something of the "haptic taste" for old media formats before they are asked to start cutting things open (for more details on this curriculum, see the Center for Analog Humanities at http:// www.analoghumanities.com).

While the Streaming Service is not, in itself, intended as an archival preservation process, it utilizes much of the same technological workflow that those processes require. The difference being that we operate at a far more cursory level - the same specialized sorts of equipment, but with less of a concern for a process's results. For example, the service uses tools like a time base corrector with a full frame synchronizer (and background signal generator) to ensure that there is no signal loss during a stream, but we are not necessarily concerned with flaws in the transmission per se. We only need to have the appropriate equipment in place to prevent the stream from terminating unexpectedly when the digital capture detects a signal loss. Archivists working with video formats tend to be concerned about output quality - carefully monitoring for noise, interference, and dropped frames. The programs we have screened on tape have degraded visual playback, tracking lines, or mild to moderate tape damage. Some of the laserdiscs are even experiencing symptoms of laser rot. We are interested in mummies, after all, not statues. Nevertheless, the actual mechanics of preparing a release rests on some of the same skills and considerations that would be employed in archival preservation.

Even here, particularities of playback force programmers to confront sometimes significant differences between the material meaning of various formats in their 
viability for remote representation. Students are often surprised to learn that Betamax, though often lauded as the superior format in its confrontation with VHS, presents far more difficulty for streaming. Though it has not necessarily aged worse, it has aged. The format wars may have started to Beta's advantage in 1976, but it took only four years for VHS to control $70 \%$ of the market. The rapid decline of the format by the early-1980s ensures that not only are there fewer home video releases, both in the number of tapes produced and titles available, but - more significantly - the median point of obsolescence falls significantly earlier (it wasn't until 1990 that the VCR finally reached a 70\% market penetration in consumer households, see Coplan 2006, 9). VHS technology, whatever its condition at the start of the 1980s, had advanced significantly by the end of the format's life. When Sony shifted to VHS in 1988, dozens of companies were producing high quality VHS decks. The few non-Sony Betamax decks, in comparison, were junk (Digital FAQ 2012).

Acquisition itself presents insights into the afterlife of video formats. Laserdisc, one of the most expensive formats in life, has become one of the cheapest in death. While rare or historic titles retain significantly more value than their videotape counterparts, the bulk of the laserdisc library can be had for next to nothing. In a bit of a historical quirk, the common size they share with vinyl LPs ensures that they turn up, unwanted, in the bulk sale of music collections. There are few record stores that actively advertise their availability, and fewer still that are interested in maintaining them. As students begin to excavate, we have come into a substantial cache of laserdiscs from crate-digging in local brick and mortar stores in New York City - most notably the now-shuttered Bleeker Street Records where several boxes could at one time be found haphazardly arranged next to the world music section in the basement. Gems from the Criterion Collection, some of which have never made the transition to DVD and Blu-ray, sat rather incongruously next to pornographic relics from a bygone era of the West Village.

The existence of the service, and its place as a regularly recurring site of dead media research, offers the opportunity to explore broader media archaeological topics related to the history of home video in an active, situated, context. This has resulted in a number of additional projects, including the performance of $8 \mathrm{~mm}$, Super-8, and $16 \mathrm{~mm}$ footage on telecine boxes, and an exploration into VHS “games" like Action Max (1987), VCR 221 B Baker Street (1987), and Nightmare (1991). In one of the more extensive, we've coupled the digital stream of the service with a more conventional broadcasting technology: analogue television transmission. Connecting the service's server to an agile modulator allows us to take the NTSC composite video source and generate a broadcast RF signal (a popular solution for vintage television collectors, see Nelson 2017). While the range is somewhat limited (the transmission covers the building floor where the server is housed), simulcasting the service on analogue television allows students to compare a contemporary "broadcast" medium with a historic one. 


\section{The psychic life of dead media}

Why do we remain so enamoured with these dusty formats, what draws us back to a diminished way of watching that, by all current consumerist logics, could be seen as radically perverse? Worse, why do we want to visit this strange habit on others? Perhaps the answer lies in a revanchist desire to return to an earlier period of cinematic culture, a time before the instant availability of video-on-demand and the constant stream of content. Between iTunes, YouTube, Netflix, and Amazon (to name just a few) it can feel like just about any film is available to view at home at the touch of a few buttons. In defiant resistance to the many epitaphs for the "death of cinema", we are overwhelmed by a glut of entertainment choices. Jeffrey Sconce has diagnosed this particular irony:

Rather than witnessing a cinema in evaporation, then, we are now increasingly buried under a cinematic avalanche. And therein lies the problem for the older cinephiliac order. Nothing is more frustrating to desire than satiation, of course, and continuing satiation must ultimately lead to torpor.

(Sconce 2004, 71)

Is the Dead Media Streaming Service a baroque reaction to this contemporary laziness? Are we just making it hard on ourselves? If this banquet of entertainment must eventually result in a decline of symbolic efficiency, then what? What happens after the orgy, as Jean Baudrillard famously asked? As Dominic Pettman notes, there is more than a little resting on our answer (Pettman 2002). Again, Sconce is instructive: "“After the orgy' of absolute cinematic access and obscenity through new distribution technologies, who knows what paraphilias cinephiles will have to devise to maintain their celluloid libidos?" (Sconce 2004, 74-75). If cinephilia is an erotics, then the Dead Media Streaming Service may seem almost necrophilic. But the objects of the past are not quite dead, and we not mired in nostalgia, but in "revival" (Parikka 2012, 3). No longer bound and buried in their old meanings, the "media undead" are put to the performance of entirely new ones.

\section{Bibliography}

Balsom, E. (2017) After Uniqueness: A History of Film and Video Art in Circulation. New York: Columbia University Press.

Benson-Allott, C. (2013) Killer Tapes and Shattered Screens: Video Spectatorship from VHS to File Sharing. Berkeley, CA: University of California Press.

Bordwell, D. (2008) The Poetics of Cinema. New York: Routledge.

Coplan, J. (2006) Diagnosing the DVD Disappointment: A Life Cycle View. The Leonard N. Stern School of Business, April 3.

Cronenberg, D. (2004) Videodrome [Director's Commentary] New York: Criterion.

Digital FAQ (2012) Is there a Betamax VCR Buying Guide? Digital FAQ Forum [Online]. Availableat:http://www.digitalfaq.com/forum/video-capture/5557-betamax-vcr-buying. html (Accessed: 10 November 2017) 
Ernst, W. (2005) Let There Be Irony: Cultural History and Media Archaeology in Parallel Lines. Art History, 28(5), November: 582-603.

Greenberg, J. (2008) From Betamax to Blockbuster: Video Stores and the Invention of Movies on Video. Cambridge: MIT Press.

Haines, R. (2003) The Moviegoing Experience, 1968-2001. London: McFarland \& Company.

Harris, M. (2008) Pictures at a Revolution: Five Movies and the Birth of New Hollywood. New York: Penguin Press.

Herbert, D. (2014) Videoland: Movie Culture at the American Video Store. Berkeley, CA: University of California Press.

Hertz, G. and Parikka, J. (2012) Zombie Media: Circuit Bending Media Archaeology into an Art Method. Leonardo, 45(5): 424-420.

Jenkins, H., Ford, S. and Green, J. (2013) Spreadable Media: Creating Value and Meaning in a Networked Culture. New York: New York University Press.

Klinger, B. (2006) Beyond the Multiplex: Cinema, New Technologies, and the Home. Berkeley, CA: University of California Press.

Lineback, N. (2017) What Do I Do with an Old Computer? Toastytech [Online]. Available at: http://toastytech.com/about/vintagecomputing.html (Accessed: 10 November 2017)

Nelson: (2017) Creating a Home TV Transmitter. Phil's Old Radios [Online]. Available at: https://antiqueradio.org/HomeTVTransmitter.htm (Accessed: 10 November 2017)

Ozer, J. (1997) The Complete Video Desktop. PC Magazine, October 7.

Parikka, Jussi (2012) What is Media Archaeology? Cambridge: Polity Press.

Peters, J. D. (2010) Introduction: Friedrich Kittler's Light Shows. In Kittler, F. (ed.) Optical Media. Cambridge: Polity.

Pettman, D. (2002) After the Orgy: Toward a Politics of Exhaustion. Albany: SUNY Press.

Sconce, J. (2004) The (Depressingly) Attainable Text. Framework, 45(2), Fall: 68-75.

Shaviro, S. (1993) The Cinematic Body. Minneapolis: University of Minnesota Press.

Siegert, B. (2011) The Map is the Territory. Radical Philosophy 169, September/October.

Sternbergh, A. (2017) “Turned Upside Down," Vulture, August 20.

Sterne, J. (2006) The MP3 as Cultural Artifact. New Media \& Society, 8(5): 825-842.

Sterne, J. (2007) Out with the Trash: On the Future of New Media. In Acland, Charles R. (ed.). Residual Media. Minneapolis, MN: University of Minnesota Press, 16-31.

Sterne, J. (2012) MP3: The Meaning of a Format. Durham: Duke University Press.

Sterne, J. (2015) Compression: A Loose History. In Parks, L. and Starosielski, N. (eds). Signal Traffic: Critical Studies of Media Infrastructures. Champaign, IL: University of Illinois Press.

Steyerl, H. (2009) In Defense of the Poor Image. e-flux 10, November.

Vintage Computer Federation (2011) Networking a 5150 to a Modern PC. Vintage Computer Forum [Online]. Available at: http://bit.ly/vcf-tween (Accessed: 10 November 2017) 